\title{
Critical Thinking as Reflected in the Sudanese and Jordanian Secondary School Certificate English Language Examinations
}

\author{
Khalid Sharif Mohammed Sharif $^{1} \&$ Ahmed Gumaa Siddiek ${ }^{2,3}$ \\ ${ }^{1}$ Open University-Jeddah, \\ 2 Qualty education Company \\ ${ }^{2}$ Al-Zaeem Al-Azhari University, Sudan \\ ${ }^{3}$ Shaqra University, KSA \\ Correspondence: Ahmed Gumaa Siddiek, Shaqra University, KSA. E-mail: aahmedgumaa@yahoo.com
}

Received: February 16, 2017 Accepted: April 8, $2017 \quad$ Online Published: April 11, 2017

doi: $10.5539 /$ elt.v10n5p37

URL: http://doi.org/10.5539/elt.v10n5p37

\begin{abstract}
This study emerges from the need of English Language Teachers in Sudan and Jordan to lay appropriate assessment strategies to meet the anticipated educational objectives among the learners of English. It is also hoped to improve language assessment in similar educational environments in the Arab world. We intended to find out the level of consistency between the educational objectives of the English language syllabus and the English language examinations in these two countries. These examinations are expected to have some beneficial washback on English pedagogy in general and on reading and writing skills in particular. These tests can be used as benchmark for the effectiveness of the teaching and the learning performance in the classroom. We found that most of the reading questions in EL examination focus on testing the low order of thinking such as knowledge and comprehension; which negatively affect the critical thinking abilities among these young learners. The study yielded many other findings but the most important is the negligence of testing speaking and listening skills which renders the standardized English language examinations in Sudan and Jordan to be incomprehensive, but on the other hand the study revealed that these examinations had some content validity.
\end{abstract}

Keywords: assessment, Sudan, Jordan, School, Certificate, language skills, critical thinking

\section{Statement of the Problem}

In this paper we will be tracing the points of strength and weakness in the school certificate English examinations in Sudan and Jordan, to measure the degree of consistency of the educational objectives of the English language syllabus as reflected by scholastic achievement examinations in both countries. The study also aims at investigating how the thinking skills in the cognitive domain of Bloom's Taxonomy of Educational Objectives could be applied in these examinations, and to what extent can language teaching help to develop some of the general educational objectives such as critical thinking within the community of the young learners of English in particular. To achieve this purpose analyses were to a pool of examinations papers and the syllabi from both countries. We as language teachers came to notice the absence of testing listening and speaking skills in these examinations. So we may infer that these examinations do not comply with the objectives of the English language teaching in both countries.

\subsection{Objectives of the Study}

This study aims at:

1). investigating the degree of comprehensiveness in both Sudan and Jordan Secondary School General Certificate English Examinations as they are expected to reflect the contents and objectives in SPINE 6 and Action Back 12 textbooks.

2). exploring the extent of content validity and representative sampling of the language skills embedded in the GSCE English Examinations.

3). exploring if the Sudan Secondary School Certificate and Jordan General Secondary Certificate English Language Examinations can be used as benchmark of effectiveness of teaching and learning performance in the classroom. 
4). finding out if these examinations have any washback on language education.

\subsection{Methodology}

The researchers used cue words in the taxonomy of critical thinking as applied to writing tasks (see appendix) as criteria to analyze the tests questions in Sudan and Jordan examinations papers from 2012 to 2015 according to the educational objectives of Bloom's Taxonomy. We have traced the mental efforts that students would exert in order to answer questions of examinations, and determine the educational objective of each one. After that we have calculated the frequency of occurrence of each educational objective and extracted percentage of each value.

\subsection{Critical and Creative Thinking of Bloom's Taxonomy}

Critical thinking, hence (CT) is about effective reasoning by using various inductive and deductive types of reasoning skills according to the situation and/or the context. (CT) is about using the system of thinking to analyze how parts of a whole interact with each other to produce overall outcomes in complex systems. See Table 1.

Table 1. Taxonomy of critical thinking as applied to writing tasks

\begin{tabular}{ll}
\hline Thinking level & Cue words \\
\hline $\begin{array}{l}\text { Knowledge (recall: remembering } \\
\text { previously learned material) }\end{array}$ & $\begin{array}{l}\text { Observe, repeat, recall, recount, } \\
\text { label/name, sort, cluster, outline, list, } \\
\text { record, match, define, memorize. }\end{array}$ \\
$\begin{array}{l}\text { Comprehension (Translate: grasping } \\
\text { the meaning) }\end{array}$ & $\begin{array}{l}\text { Recognize, express, locate, explain, } \\
\text { identify, review, restate, cite, } \\
\text { paraphrase, document/ support, tell, } \\
\text { describe, summarize, report, précis/ } \\
\text { abstract. }\end{array}$
\end{tabular}

Application (Generalize: using the Select, use, dramatize, illustrate, material in new and concrete manipulate, sequence, imagine, situations) show, organize, imitate, demonstrate, frame

Analysis (Breakdown /discover: breaking down material so that it is more easily under-stood)

Synthesis (compose: putting materials together to form a new whole)

Examine, classify, outline, map, research, interpret, refute, conclude, infer
Propose, plan, compose, formulate, design, construct, emulate, imagine, create, invent

\section{Sample directions}

Recall names and prelateship of characters in a drama. Cluster the characteristics of the author style. Define denotation and connotation.

Explain how words and actions affect our perception of a play's characters. Restate the story of (character) in your own words, incorporating all parts contributed by the class.

Imitate a story by writing about a similar event in your own life.

Apply the definition of a word as it is used in a story to another situation. question, analyze, compare,

Analyze which letter from a group of friends would be the most persuasive.

Examine Thanksgiving from the points of view of a child, a parent, and a turkey.

Imagine you've discovered a new animal; write an encyclopedia entry for it.

Speculate about a person based on a photograph.

Compose an alternate ending for a story.

Evaluation (Judging the value of Compare, rank, judge, rate, material for a given purpose) evaluate, predict, criticize, argue, justify, convince, persuade, assess, value.
Persuade a specific audience through a letter. Assess a character's action in term of its value. Assess the overall learning experience of doing $a$ writing assessment.

\footnotetext{
Source: Topics in the English/Language Arts Curriculum. Page 76.
} 
Critical Thinking is about making sound Judgments and taking right decisions by effectively using analysis and to evaluate evidence, arguments, claims and beliefs. It is to evaluate major alternative points of view by synthesizing and making connections between information and arguments. So if we followed these steps then we would be able to interpret information and draw conclusions based on the best analysis, to reach the ultimate of learning: to be able to Solve Problems in different kinds of non-familiar problems in both conventional and innovative ways. Benjamin Bloom (1956) developed a classification of levels of intellectual behavior in learning. This taxonomy contained three overlapping domains: the cognitive, the psychomotor and the affective.

\subsection{Critical Thinking and Foreign Language Learning}

According to (Castillo, 2000) in (Lopez et al., 2017) language is the vehicle of thinking processes and processes of thinking can be effectively shared with the use of (spoken or written) language. Language embodies thinking and critical thinking (CT) is expressed normally through written and spoken language (Castillo, 2000).

But the application of critical thinking for teaching and learning foreign language (FL) is a new area of investigation (Alnofaie, 2013, p. 155). As (Lopez, 2017) stated that most of the studies on CT in relation to L2/FL learning done in Asia started early in 2000.

Lopez(ibid) says that in the Philippines it was found that language proficiency influences critical thinking and that language proficiency and CT are significantly related. These findings were found in Javier (2001) where she claims that a significant change in language proficiency may significantly affect the critical thinking of the students.

Javier (2001) as in (Lopez) concluded that CT is essential in learning the macro skills of language: listening, speaking, reading, and writing and that language proficiency have a direct impact on CT skills.

In an earlier attempt in 2004 Lopez developed and validated CT infusion lessons in communication skills for Filipino college students using Ennis' concept (1996) of CT as his theoretical framework.

Rashid and Hashim (2008) examined the CT ability of Malaysian undergraduates and its relationship to language proficiency and found that there is a correlation between CT ability and English language proficiency as in (Lopez, 2017).

Many researchers found significant relationships between critical thinking and language such as (Fahim and Komijani (2010), Grosser and Nel (2013, Hashemi and Zabihi (2012), Lin and Mackay (2004), Lai (2011); Fahim and Hajimaghsoodi, (2014). Critical thinking as in (Lopez, 2017), is a necessary precondition to foreign language learning. These beliefs are also supported by (Dörnyei, 2001; Gardner, 1985; Gardner \& Lambert, 1959; Gonzales, 2010, 2011; Ushioda, 2001, 2008; Lai, 2011; Fahim \& Hajimaghsoodi, 2014), in Lopez (ibid).

\subsection{Critical thinking and language Examinations}

Bloom's Taxonomy is naturally involved in the instructional design process. It is a great way to determine how much your learners understand. The initial focus was primarily for academia and now finds a comfortable place in training programmes. Bloom and associates identified three domains of learning:

Cognitive: mental skills, intellectual capability (knowledge)

Affective: feelings, motivation, behavior (attitude)

Psychomotor: manual or physical skills (skills)

These are sometimes identified as "Do-Think-Feel" or KSA (Knowledge, Skills, and Attitude). The application of the six levels of Bloom's Taxonomy represents a hierarchy of learning that goes from the simple (level 1) to the complex (level 6). Bloom's Taxonomy could be used in structuring questions; this is how it applies to the testing process.

1). Knowledge - to check learner ability to recall basic information

2). Comprehension - confirm understanding

3). Application - use or apply knowledge

4). Analysis - interpret elements; break the information into smaller parts

5). Synthesis -create/develop plans; put pieces together to form a new whole

6). Evaluation - judge, assess, critical thinking (see Langevin Team-online).

In this final level of Bloom's Taxonomy, you may ask the learner to offer opinions, criticize, judge, recommend, 
justify, evaluate, or explain which option is better, based on a set of knowledge and criteria.

Using Bloom's taxonomy in instructional design is an excellent way to help gauge the level of knowledge amongst your learners. It can easily be integrated into the design process. We were taught to answer five basic types of questions; who, what, when, where and how if we want to write an article, but here are three different question types that can be used to extract the target behaviour value that we want to test (see Langevin Team-online).

1) Knowledge Question; to test a learner's ability to recall basic information.

2) Comprehension Question: to find out if a learner understands the meaning of something.

3) Application Question: to see if a learner can apply concepts to a real world environment.

\section{Description of Language Syllabus in Sudan and Jordan}

English pedagogy attracts great care in both countries; as higher institutes in Sudan and Jordan use it as medium of instruction, especially in teaching sciences and applied sciences such as medicine and engineering.

In the Sudan School English Examinations there are five sections, four parts are compulsory and the fifth is divided into two optional sections. The testee can answer section (A) which comprises questions taken from SPINE series, or respond to section (B) that includes literature questions. While Jordanian General Secondary Certificate English Language Examinations are administered in in two sessions, one in winter, always held in January and the other in summer in July. All the questions in these sessions are compulsory

\subsection{The Thinking Skills English Language Exams in Sudan and Jordan from 2012 to 2015}

The cognitive domain involves knowledge and the development of intellectual skills (Bloom, 1956). This includes the recall or recognition of specific facts, procedural patterns, and concepts that serve in the development of intellectual abilities and skills. In Table 1 - see Table 2 is a summary of the weight of each educational category embedded in the exams in both countries.

Table 2. The thinking skills in Sudan and Jordan English language Exams from2012 to 2015

\begin{tabular}{|c|c|c|c|c|c|c|c|}
\hline Year & Country & knowledge & comprehension & Application & Synthesis & Evaluation & Total \\
\hline \multirow{8}{*}{2015} & \multirow{2}{*}{ Sudan (literature) } & 40 & 5 & 17 & 2 & 0 & 64 \\
\hline & & $62.5 \%$ & $7.8 \%$ & $26.6 \%$ & $3.1 \%$ & $0.0 \%$ & $100 \%$ \\
\hline & \multirow[t]{2}{*}{ Sudan (language) } & 15 & 10 & 22 & 2 & 0 & 49 \\
\hline & & $30.6 \%$ & $20.4 \%$ & $44.9 \%$ & $4.1 \%$ & $0.0 \%$ & $100 \%$ \\
\hline & \multirow[t]{2}{*}{ Jordan Winter } & 2 & 14 & 5 & 2 & 2 & 25 \\
\hline & & $8.0 \%$ & $56.0 \%$ & $20.0 \%$ & $8.0 \%$ & $8.0 \%$ & $100 \%$ \\
\hline & \multirow[t]{2}{*}{ Jordan Summer } & 2 & 17 & 2 & 2 & 2 & 25 \\
\hline & & $8.0 \%$ & $68.0 \%$ & $8.0 \%$ & $8.0 \%$ & $8.0 \%$ & $100 \%$ \\
\hline \multirow[t]{8}{*}{2014} & \multirow[t]{2}{*}{ Sudan (literature) } & 40 & 5 & 17 & 2 & 0 & 64 \\
\hline & & $62.5 \%$ & $7.8 \%$ & $26.6 \%$ & $3.1 \%$ & $0.0 \%$ & $100 \%$ \\
\hline & \multirow[t]{2}{*}{ Sudan (language) } & 15 & 10 & 22 & 2 & 0 & 49 \\
\hline & & $30.6 \%$ & $20.4 \%$ & $44.9 \%$ & $4.1 \%$ & $0.0 \%$ & $100 \%$ \\
\hline & \multirow[t]{2}{*}{ Jordan Winter } & 2 & 14 & 5 & 2 & 2 & 25 \\
\hline & & $8.0 \%$ & $56.0 \%$ & $20.0 \%$ & $8.0 \%$ & $8.0 \%$ & $100 \%$ \\
\hline & \multirow[t]{2}{*}{ Jordan Summer } & 3 & 13 & 5 & 2 & 2 & 25 \\
\hline & & $12.0 \%$ & $52.0 \%$ & $20.0 \%$ & $8.0 \%$ & $8.0 \%$ & $100 \%$ \\
\hline \multirow[t]{7}{*}{2013} & \multirow[t]{2}{*}{ Sudan (literature) } & 40 & 5 & 17 & 2 & 0 & 64 \\
\hline & & $62.5 \%$ & $7.8 \%$ & $26.6 \%$ & $3.1 \%$ & $0.0 \%$ & $100 \%$ \\
\hline & \multirow[t]{2}{*}{ Sudan (language) } & 15 & 10 & 22 & 2 & 0 & 49 \\
\hline & & $30.6 \%$ & $20.4 \%$ & $44.9 \%$ & $4.1 \%$ & $0.0 \%$ & $100 \%$ \\
\hline & \multirow[t]{2}{*}{ Jordan Winter } & 2 & 14 & 7 & 2 & 2 & 27 \\
\hline & & $7.4 \%$ & $51.9 \%$ & $25.9 \%$ & $7.4 \%$ & $7.4 \%$ & $100 \%$ \\
\hline & Jordan Summer & 2 & 15 & 6 & 2 & 1 & 26 \\
\hline
\end{tabular}




\begin{tabular}{lllllll}
\hline \multirow{2}{*}{2012} & $7.7 \%$ & $57.7 \%$ & $23.1 \%$ & $7.7 \%$ & $3.8 \%$ & $100 \%$ \\
Sudan (literature & 40 & 5 & 17 & 2 & 0 & 64 \\
& $62.5 \%$ & $7.8 \%$ & $26.6 \%$ & $3.1 \%$ & $0.0 \%$ & $100 \%$ \\
Sudan (language) & 15 & 10 & 22 & 2 & 0 & 49 \\
& $30.6 \%$ & $20.4 \%$ & $44.9 \%$ & $4.1 \%$ & $0.0 \%$ & $100 \%$ \\
Jordan Winter & 2 & 15 & 6 & 2 & 2 & 27 \\
& $7.4 \%$ & $55.6 \%$ & $22.2 \%$ & $7.4 \%$ & $7.4 \%$ & $100 \%$ \\
Jordan Summer & 2 & 15 & 6 & 2 & 2 & 27 \\
& $7.4 \%$ & $55.6 \%$ & $22.2 \%$ & $7.4 \%$ & $7.4 \%$ & $0.0 \%$ \\
\hline
\end{tabular}

\subsubsection{Knowledge}

As in Figure 1 the percentage of knowledge in Jordan exams from 2012 to 2015 is (8.3\%), whereas the percentage of knowledge educational objective in Sudan exams from 2012 to 2015 is (19.7\%) in case that the learner did not answer the literature section but if the candidate answer the literature questions the percentage will increase and become (52.6\%). The answers of all questions of knowledge thinking skill in Sudan and Jordan examinations are textually explicit. The student can simply find the answer by just remembering the keywords in the question. Knowledge objective also exists in the optional section of literature in the Sudan examinations. According to his/her previous reading, the learner will just recollect the incident that took place in the story and write the answer.

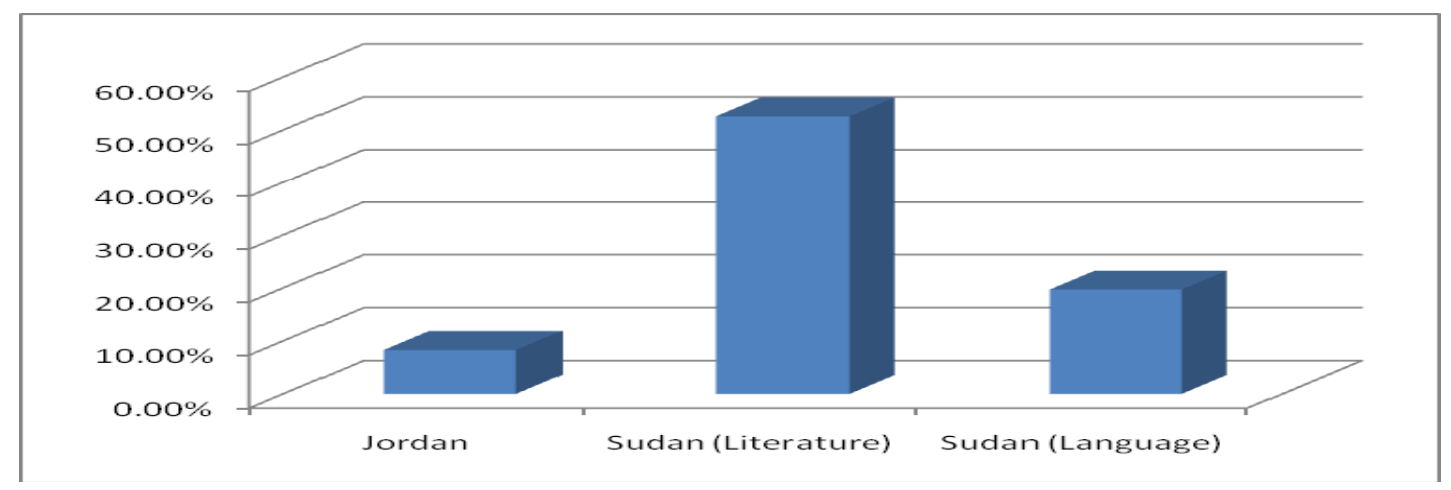

Figure 1. Knowledge

\subsubsection{Comprehension}

As in Figure 2 blow, the percentage of the comprehension objective in Bloom's taxonomy in Jordan exams from 2012 to 2015 is estimated at (\%56.6), however the percentage for the same educational objective in Sudan exams from 2012 to 2015 is (\%6.6) if the student answered the literature section and (\%13.2) if $\mathrm{s} / \mathrm{he}$ answered the language questions taken from SPINE series. In both Sudan and Jordan examinations, the candidates can answer the comprehension questions whether by inferring the correct synonyms, using the mnemonic words as indicators to the location of the right answer or determining the correct reference of the pronouns or the relative pronouns. 


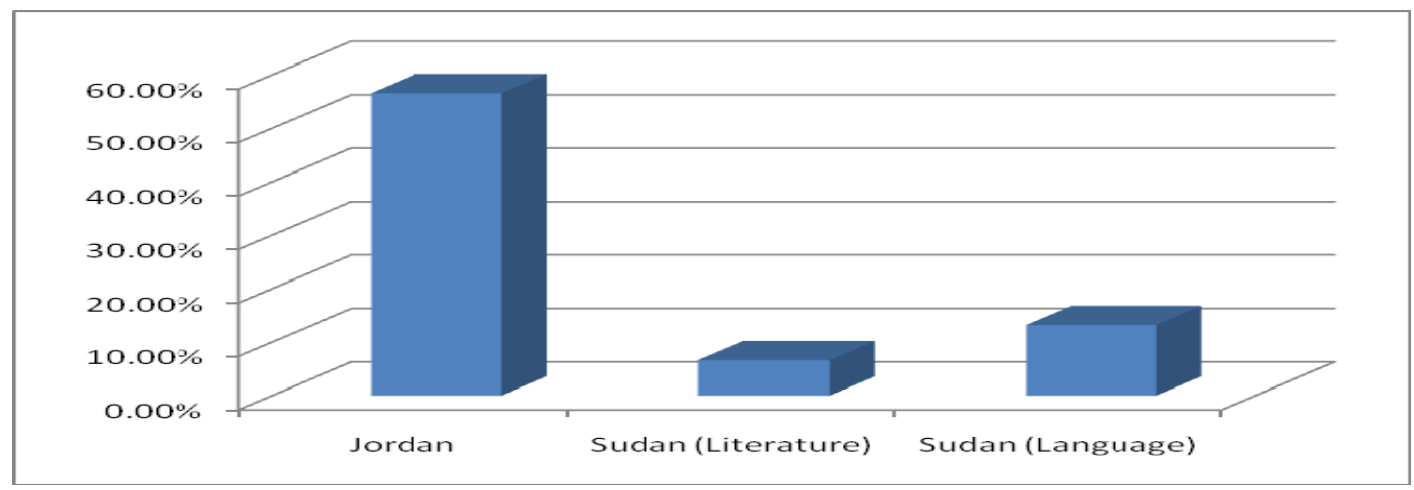

Figure 2. Comprehension skill (2012-2015)

\subsubsection{Application}

As in Figure 3 below the application thinking skill in Jordan exams from 2012 to 2015 represents (20.4\%) of the total questions, yet the same thinking skill in Sudan exams during the same period is estimated at $(22.4 \%)$ if the student answer the optional question of literature. On the other hand, the percentage increases to (29\%) if the candidate selects the language section.

In both Sudan and Jordan exams, the questions of the application thinking skill varies from choosing the correct verb, completing a sentence using certain grammatical rule or writing the correct form of the infinitive, which is already given in brackets. In both countries the exams from 2012 to 2015, the researchers did not find any question that addressed the Analysis thinking skill. In assessing the capability of a student to analyze, s/he may be exposed to questions concerning some material with which s/he is supposed to be familiar, or the material for analysis may be offered to him in the test situation. When an analysis question is appropriate and new to the student, it is expected to be a valid and reliable test of his analytical abilities, because student would have no chance to use analytical comments which s/he simply remembers from previous discussions of the material. The student may show his ability by making a series of free or guided answers, or by choosing the best. The material given for analysis in a test may be a social situation, a set of data, an argument, a picture or a literary passage to be analyzed literary or linguistically. Or the student may be placed in an actual situation, such as a classroom in which $\mathrm{s} / \mathrm{he}$ analyzes the interactions of members of the group.

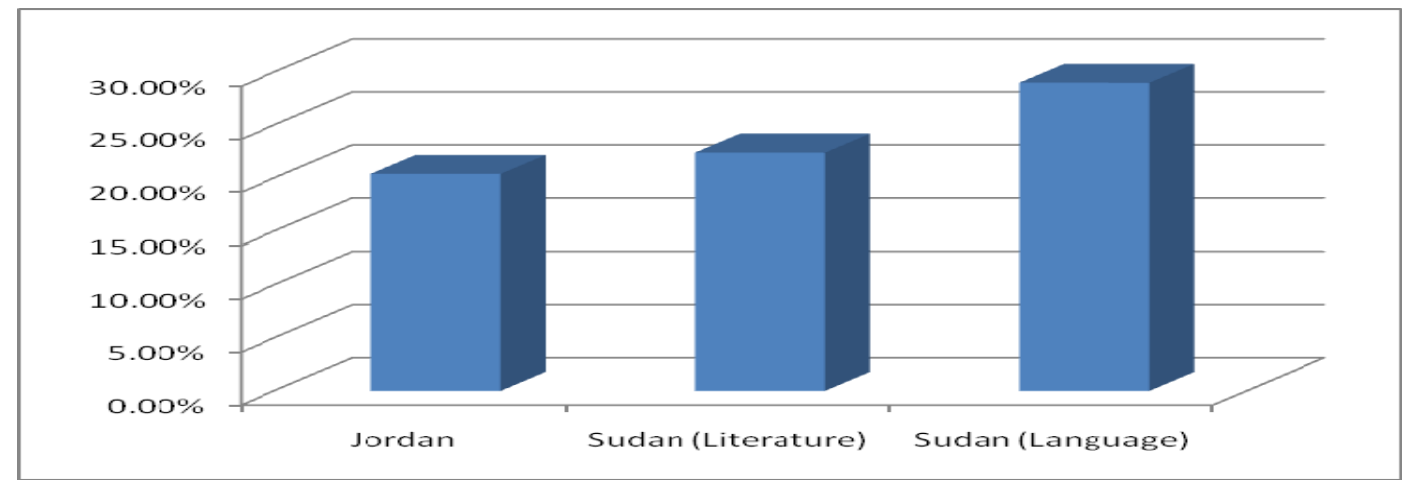

Figure 3. Application skill (2012-2015)

\subsubsection{Synthesis}

As in Figure 4 synthesis is found as (7.8\%) in Jordan exams while in Sudan exams, if the testee answered the literature questions the synthesis thinking skill will be found as $(2.6 \%)$ of the total questions and $(5.2 \%)$ if $\mathrm{s} / \mathrm{he}$ responded to the language section. Answering the questions of the synthesis objective, the testee should use the information given to him/her in the question to write a letter, summarize a long paragraph as in Sudan examinations, or show more critical thinking and write his own ideas and suggestions as can be seen in Jordan examinations. The sentences should be structurally accurate, connected by the suitable conjunctions. 


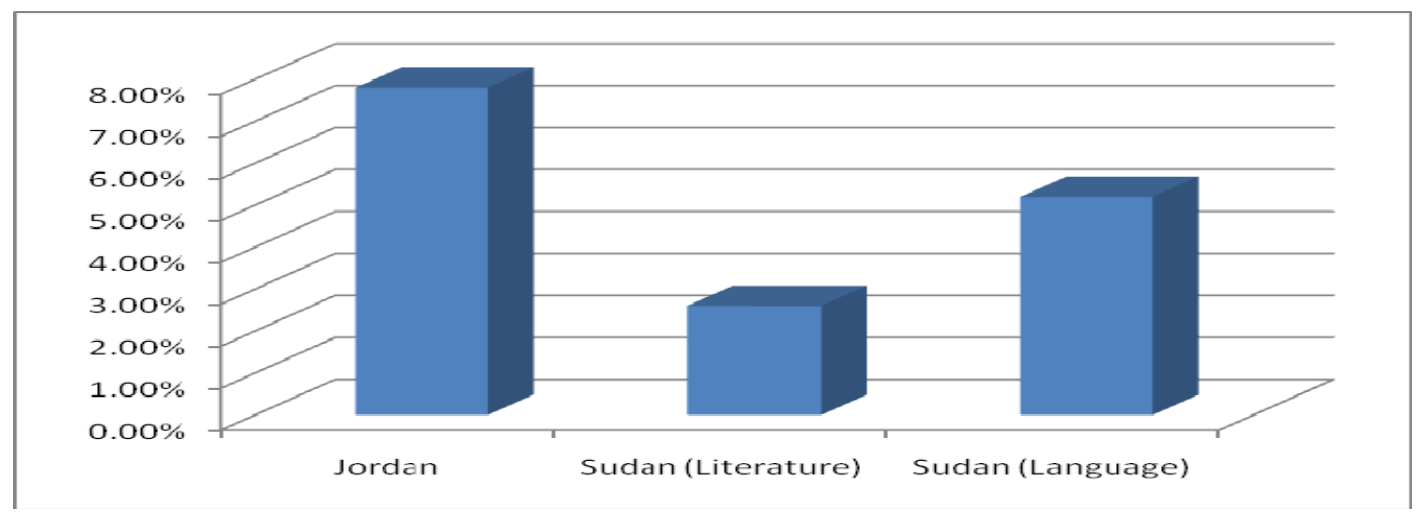

Figure 4. Synthesis skill (2012- 2015)

\subsubsection{Evaluation}

As can be seen in Figure 5 below evaluating educational objective is estimated at (7.3\%) in Jordan exams. This thinking skill cannot be seen in Sudan exams from 2012 to 2015. In Jordan General Secondary Certificate English Language Examinations from 2012 to 2015, the evaluation thinking skill can be seen in critical thinking questions where students are asked to write judgments concerning certain experiences such as building tunnels, oversleeping, how the introduction of modern technology can be beneficial to the productivity of traditional crafts...etc. Jordanian candidates were also asked to write free compositions of about 80 words concerning a specific topic. The testee had to justify his/her own ideas and judgments, and write about the different dimensions of the topic using comprehensive information with appropriate linking words, without spelling mistakes.

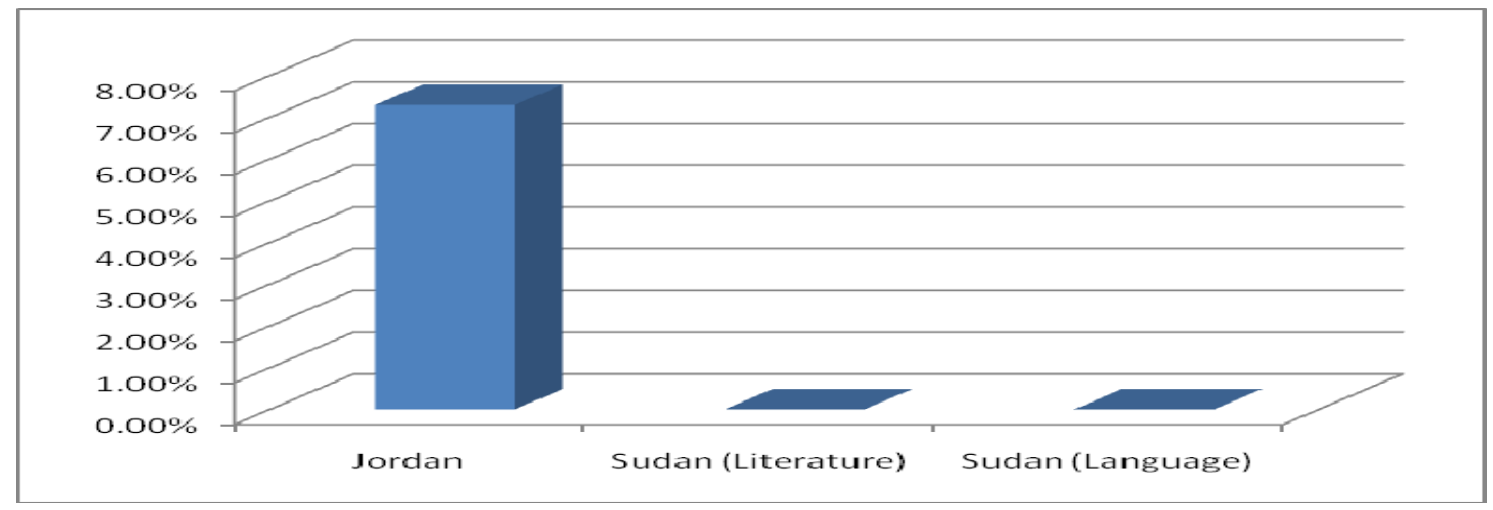

Figure 5. Evaluation skill (2012-2015)

By applying Bloom taxonomy in English language tests, we can determine the aims that we aspire to achieve from the teaching of English language. This can be done by designing questions that address these objectives and reflect the effectiveness of the teaching of these goals inside the classroom. Moreover, the application of Bloom's taxonomy in English language tests clarifies to what extent student can benefit from the teacher and the syllabus as well.

\subsection{Analysis of Action Pack 12 and SPINE6}

Analyzing the syllabuses in general and textbooks in particular plays a vital role in the assessment of the credibility and feasibility of EFL teaching and learning resources and processes. It helps supervisors, textbooks' designers and researchers to discover the points of strength and weakness in the textbook and to what extent it is suitable for both students and teachers. SPINE and Action Pack series are English language syllabuses for basic and secondary level in Sudan and Jordan. They consist of materials asserting that English language teaching should be interactively taught and evaluated in light of the basic concepts of the communicative approach. 
In SPINE6 and Action Pack 12, all activities and tasks in these textbooks stemmed from the title of the chapter or module. These syllabuses also use the techniques of the functional language practice and the integrated approach The integrated approach as defined by Richards and Schmidt (2010) aims at "the teaching of the language skills of reading, writing, listening and speaking in conjunction with each other as when a lesson involves activities that relate listening and speaking to reading and writing". We counted the activities of each skill throughout the whole textbooks of SPINE 6 and Action Back12, and extracted the percentage of each skill in the two syllabi.

\subsubsection{Description of Action Pack12}

Al-Ghazo and Samdi (2013) mention that in 2006,the Jordanian Ministry of Education stated a list of guidelines that stress the integral role of foreign language education in developing the Jordanian students in the four language skills and psychomotor, social, cognitive and cultural domain. These guidelines focus on the following:

(a) An emphasis on knowledge economy competencies: educating students to be innovative thinkers who can analyze, and communicate information and work with one another to create a prosperous knowledge economy for all.

(b) Integration of information and communications technologies: ensuring students use technological devises and processes to broaden and deepen their learning.

(c) New role for students: giving students opportunities to define their own ways of reaching outcomes.

(d) New role of teachers: emphasizing that the new role of teacher is to help students learn and communicate effectively by giving greater consideration to the individual learning needs.

(e) Variety of instructional strategies: selecting appropriate instructional strategies to ensure that all students achieve learning goals.

(f) New way of assessment strategies and tools.

"The English language curriculum in Jordan is one of the basic and compulsory school subjects. Action Pack is a real outcome of the recommendations that resulted from the conferences of Education development. It was introduced to Jordanian schools to be taught from grade one until twelfth grade." (Al-Ghazo \& Samdi, 2013).

Haines (2010) mentions that the Action Pack series offers learners:

- Modern, interesting and relevant topics.

- A clear and systematic approach to grammar, with thorough practice.

- Integrated skills work with a particular focus on reading and writing.

- Consistent building and recycling of vocabulary.

- Special sections devoted to functional and situational language.

- Project work at the end of every module.

- The development of critical thinking skills.

Each level of Action Pack consists of a Student's Book, Audio Cassettes, a Workbook and a comprehensive Teacher's Book. Action Back 12 student's book is the main textbook that prepares the Jordanian students for the Jordan General Secondary Certificate English Language Examination. This textbook is divided into 4 modules, each one concentrates on a specific topic. Each module comprises three units that probe the topic in different ways. For example, module one consists of three units which are; The Law, Migration and Precious Resources. see Table 3 here that shows the outcomes in Action Pack per Module. 
Table 3. The outcomes in Action Pack per Module

\begin{tabular}{lll}
\hline Module & Outcomes & No. of pages \\
\hline Module 1 & By the end of this module, the student will be able to... & 15 pages \\
a) listen to a lecture and a description, and demonstrate understanding. & \\
b) recall past events. \\
C) talk about wishes. \\
d) write a report based on statistics. \\
e) scan for specific information. \\
f) present ideas and suggestions. \\
g) write an essay. \\
By the end of this module, the student will be able to... \\
a) listen to a talk and description, and demonstrate understanding \\
b) give explanations and describe experiences \\
c)talk about cause and effect \\
d) read for gist and detailed information \\
e)give opinions / make decisions \\
f)present ideas and suggestions \\
g) write an account of a visit. \\
By the end of this module, the student will be able to.. \\
a) listen to a talk and a description, and demonstrate understanding. \\
b) compare and contrast. \\
c) infer meaning. \\
d) write a biography. \\
e) give advice. \\
f) write a magazine article. \\
By the end of this module, the student will be able to. \\
a) solve logical problems. \\
b)talk about past and present actions. \\
C)listen for specific information. \\
d) wake difficult choices \\
module 4 \\
\hline
\end{tabular}

These outcomes which are written at the opening of each module cope with and are related to the integrity of listening, speaking, reading and writing skill, and the interaction between learners and teachers. In each unit of Action Pack 12, there is regular, practice in reading, listening, speaking and writing, where the stress is on practice and production of language. Many chances are available for learners to improve critical thinking skills and show their own views and ideas through every unit and particularly in the project at the conclusion of each module.

2.2.2 Action Pack 12 Textbook and the Integration of the 4 Skills

Satisfaction of the educational needs and interest of Grade 12 students in Jordan is the main purpose for designing the textbook of Action Pack 12.

The course also aims at broadening students' general knowledge, through text-based work within the topics, and vocabulary development. The Student's Book is divided into 4 modules; each one is focusing on a particular topic, and contains 3 units, which develop the topic in different ways. Action Pack 12 makes it clear that foreign language teaching has changed from just focusing on the language components; grammar, vocabulary, and pronunciation to a emphasize on the communicative proficiency and the integration of four skills: listening, speaking, reading and writing. 
From the representation of the 4 Skills in Action Back121 as it appears in the graph - see Figure 6 below, the productive skills represent the largest proportion since they form $59 \%$ comparing with $42 \%$ for the receptive skills throughout all the activities and tasks of the whole textbook. Each module begins with an opener which consists of two pages.

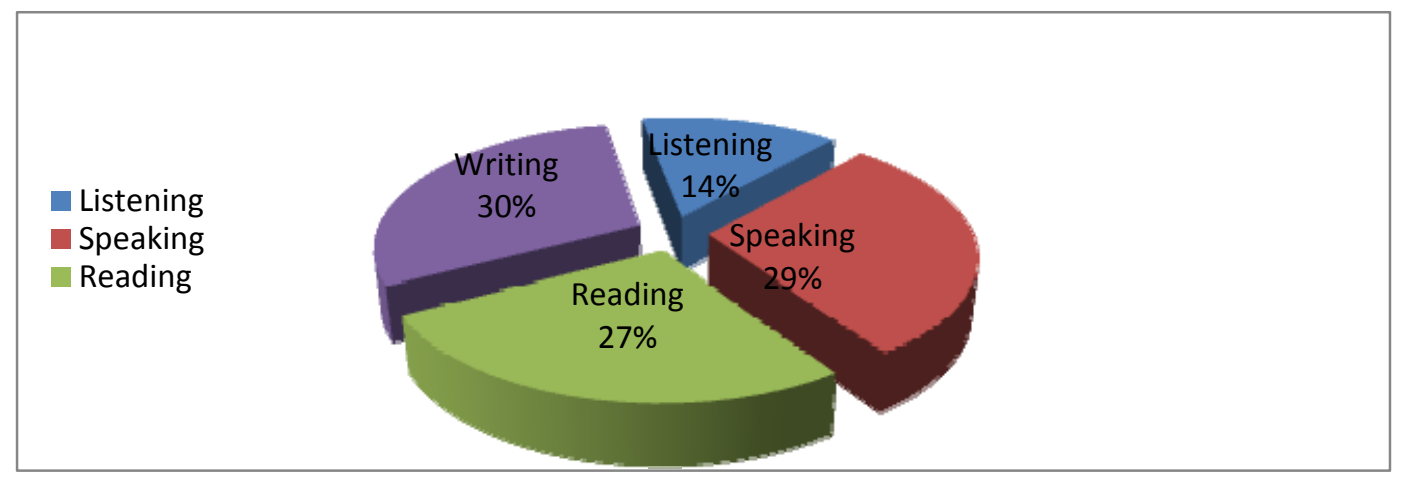

Figure 6. Representation of the 4 skills in Action Back12

This offers the students a chance to speak because they predict and foretell what the module is going to be about. The Opener always contains pictures taken from the different units of the module. In the Opener, the objective of each module and the titles of the three unites are shown besides some questions to be thought of and discussed by the learners. Each module consists of three units and each unit starts with a Unit summary which shows tasks and activities under six headings. These six headings are grammar, vocabulary, listening, reading, writing and speaking.

Table 4. The topics of the main reading passages in the textbook of Action Back12

\begin{tabular}{ll}
\hline The Module & The topic \\
\hline Module One & 1- Why do people leave their home countries? \\
& 2-Recycling in Jordan. \\
Module Two & 3-Waste and recycling 2004-2010: Key facts. \\
& 1-The spread of the desert. \\
& 2-A whole planet under glass. \\
Module Three & 3-Our Visit to Wadi Rum \\
& 1-A magazine article. \\
& 2- The end of village life. \\
Module Four & 3- Self-taught success. \\
& 1- Climbing Everest. \\
& 2- Recent developments in transport technology. \\
& 3- So Talented, so young.
\end{tabular}

The reading passages are introduced with a short activity for the learners to be performed as they are listening or reading. For example, on page 16, there is an introductory task, related to the text, "Why do people leave their home country?" It tells the reader that before he reads the article on page $17, \mathrm{~s} /$ he has to guess and match the words and phrases with their meanings, e.g:
a. success
b. development
c. deteriorate
d. emigrate

\section{1- economic activity concerned with raw materials and manufacture goods.}

2- a serious shortage of food leading to great hunger on a large scale

3- a period of great wealth

4- the process of modernization 
e. famine

f. industry
5- to leave your country to live in a new country

6 -to get worse

The reading passages usually contain sentences or phrases that are going to be studied later in the grammar section. The first, or 'gist' reading or listening section helps students to understand the general areas of information presented. There is also a 'Check your understanding' section which has more detailed comprehension questions. Learners need to listen or read several times to complete many activities.

In Action Pack12, there are (Factfiles) attached to some reading passages which cover valuable facts about the topic that is going to be taught. These can be used in various ways; for example, asking the students what they already know about the information under each heading before reading it. For example, on page 70, in Module4, chapter10, we can find This Factfile attached to the reading passage of "Climbing Everest".

Factfile:

Chomolungma is the Nepalese name for Mount Everest.

- At 8,848 metres, or 29,029 feet, above sea level, Mount Everest is the highest mountain in the world.

- Over 200 climbers have died while attempting to scale Mount Everest.

- By the end of 2008, there had been 4,102 ascents to the summit of Everest.

- On May 25, 2008, 76-year-old Min Bahadur Sherchan became the oldest person to climb Mount Everest.

- The youngest person to date to climb Mount Everest is Temba Tsheri, a

Nepalese boy who climbed to the summit on May 23, 2001 at the age of 15.

Vocabulary tasks and activities are essential features of each unit. These activities concentrate on vocabulary from the reading passages and improve new, related topic areas, e.g: the phrasal verbs, idioms and word families. There are many vocabulary tasks such as matching, filling in the spaces, classifying, listing and identifying pictures. The Grammar tasks and activities focus on the grammar of the unit. The examples used in this section are usually sentences or phrases taken from the reading or listening texts to help students discern the grammar rules. For example, on page 45 there is grammar activity related to the text "The Sand Gazelle"

Here is an example: Note the passive verbs in these sentences.

a. Sand gazelles are protected from predators by camouflage.

$b$. They are excellent jumpers and their speed and agility are used to evade the attention of predators.

c. If sand gazelles are being threatened, they can run away.

d. This project was started in 1979 and there have been some successes.

Each unit consists of either one or two 'Useful language boxes'. These are designed to help students be ready for writing or speaking task. "The skills syllabus provides regular, carefully-staged practice in reading, listening, speaking and writing, where the emphasis is on practice and production of language". (Kilbey,2010)

Useful language boxes offer examples of words and grammatical rules that are suitable for practicing speaking or writing. The practice of writing in Action Pack 12 plans for improving a specific real life writing skill that the learners may need to use during their future life. These involve activities such as writing emails, filling in applications, writing reports and writing recommendation letters. An example of this can be seen on page 61, where the student is asked to write an email of 120 to 150 words suggesting a suitable place for a family to live in.

Action Pack 12 also offers the learners chances to practice what they have been taught by working on a project. Factfile offers extra data about a particular topic. The students can use these facts to support a listening task or a writing task, or to participate in a group work. In this part, teachers have an essential role in leading and aiding the students about how the best performance of the factfile can be achieved. Many units contain 'Quote box'. This includes a quotation, taken from famous writer, or an expert concerning certain theme. The quotation usually speaks about an interesting thought that is expressed in small number of words. It is considered as a kind of general comment on the main topic of the module.

\subsection{Description of SPINE 6 Textbook}

In SPINE6 Teacher's Book, according to Alfaki (1997), there are three aims of these textbooks; as by finishing SPINE 6, pupils should have: 
(a) Recycled and reinforced previously learned language.

(b) Developed further the four language skills with special emphasis on Reading and writing.

(c) The ability to understand and use English which is relevant to their needs and which will help them to communicate with adequate accuracy and fluency in all situations.

SPINE 6 comprises ten chapters, each chapter contains five sections. Section one and two consist of activities designed to develop speaking, reading and writing skills. Section one always begins with two or three pre-reading brainstorming questions dedicated to urge students to discuss some aspects of the topic of the chapter. These pre-reading questions offer students good chance to practise speaking English. The passages in section one are generally longer. They are formed to offer students chances to read for information, comprehension and entertaiment. There are different kinds of texts in section two such as letters, dialogues, advertisements, diagrams,etc... The targets of section one and two are to introduce learners to varied sorts of reading texts and various styles of writing. In section three, students concentrate on vocabulary, grammar ad tenses. They use them together in a communicative context. Section three includes the following activities:

a) Working with Words: This activity offers learners the chance to study, consolidate and practise different aspects of a word such as, meaning,form, spelling and pronunciation.

b) Grammar Corner: this activity aims at giving students better understanding of how the tenses work.

Students should use these activities to practise the real use of English language communication. Section four is mainly concerned with writing. It covers various writing types, such as descriptive writing, dialogues and conversations, letters, advertisements, narrative and summary writing. This section contains the following activities:

a) Read This:Student read a model similar to the kind of writing that they are going to write about. The model is tailed by questions which make the students concentrate on the main features of that kind of writing.

b) Step by Step: Here, the students will perform guided execises and answer questions which will help them to practise the features of the writing task that they will write about.

c) Over to You: After the preparation offered in the two preceding

activities, the learner is now asked to perform the writing task.

Section 5 challenges students to think and have fun through brain teasers, riddles, games, stories, jokes,songs and proverbs. This section is a good chance for students to use the English language in a communicative setting. As can be seen in Figure 7; there is complete absence of the listening skill in the textbook of SPINE6.

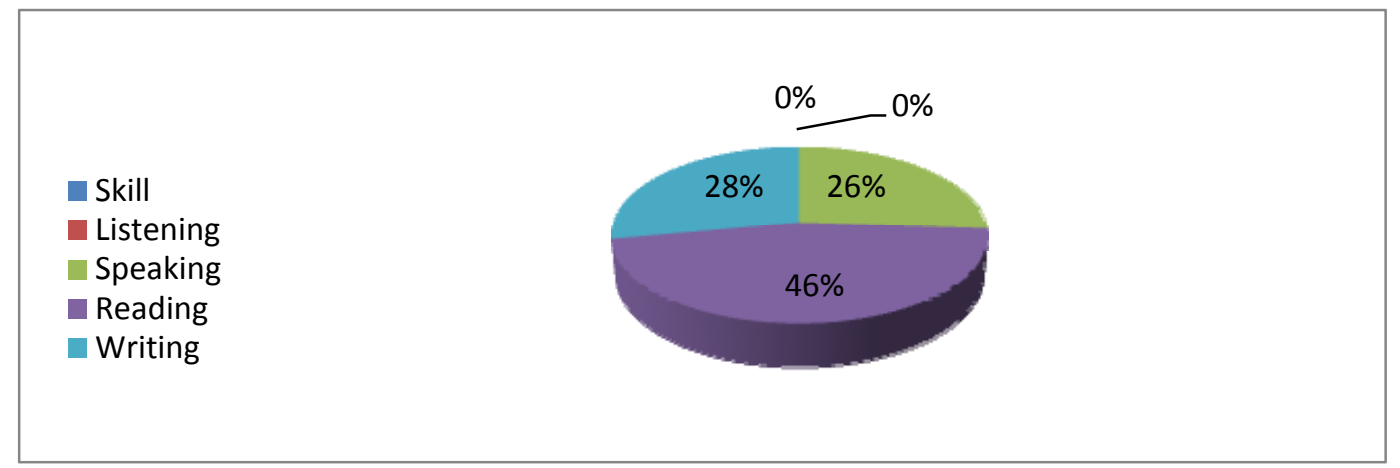

Figure 7. The distribution of the four skills in SPINE 6

Paris (2013) believes that the listening skills are important not only for the pedagogical and professional needs but also for understanding how to practice good communication in your daily life between friends, family, and others. Listening skills are important because they foster good self-esteem, maximize productivity, improve relationships and assist in becoming a fluent speaker.

The absence of the listening skill activities in SPINE 6 textbook absolutely contradicts the objectives of the Ministry of Education of language education. One of the main objectives of SPINE 6 is to develop the four language skills with special emphasis on Reading and writing. The complete absence of the listening skills 
activities and tasks may be due to the unavailability of the technical devices such as language laboratory, tape recorders or CD players.

The productive skills, speaking and writing, got the lion's share $54 \%$ of the activities and tasks throughout the whole textbook. Speaking activities can be clearly seen at the beginning of each section, where the pre-reading questions offer learners a good opportunity to speak and discuss issues stemming from the topic of the text.

The writing skill represents $28 \%$ of the activities throughout the whole textbook of SPINE 6 . The writing activities include information about steps of writing a paragraph, the usage of the cohesive devices such as connectors for developing a coherent text, putting the sentences in the correct order, writing a summary, writing from notes and comprehending the differences between formal and informal writing.

The activities and tasks of the reading skill represent $46 \%$ of all the activities and tasks throughout the whole textbook of SPINE 6. The pre-reading activities provide the students with vocabulary related to the text that they are going to read. The reading texts concentrate on topics culturally related to the daily life of learners.

Table 5. The topics of the main reading passages in the textbook of Spine 6

\begin{tabular}{ll}
\hline The Chapter & The topic \\
\hline Chapter One & 1-Forests. 2- The spine Gum Arabic Scheme.3-Trees for Fuel. \\
Chapter Two & 1-Job Hunting. 2-Two Wheels: are they worth the risk? \\
Chapter Three & 1-Tito and Tina. 2- Martin Luther King. \\
Chapter Four & 1-Education.2-Girl's Education: A luxury or a right? \\
Chapter Five & 1-Women's Participation: Life Line for Development \\
Chapter Six & 1-Food for Life. 2- Living to eat or eating to live? \\
Chapter Seven & 1-Economic development. 2- The sweet Smell of Success. \\
Chapter Eight & 1-A World of Difference. 2- Fashion. \\
Chapter Nine & 1-Agatha Christie's Life. 2- the Truth. \\
Chapter Ten & Nuclear Power. 2- Alternative energy. \\
\hline
\end{tabular}

The reading texts in SPINE 6 are to some extent culturally appropriate to students. They concentrate on topics related to the everyday life of the Sudanese people. These topics can activate the schemata of the students and make them interact inside the classroom by the virtue of the previous knowledge that they have about these topics.

These reading texts consist of topics such as environment, development issues, the difference between urban and rural lifestyles, Sudanese hospitality, women's issues, technology, employment and international literature. While the content of the reading passages are related to the daily life of students, the vocabulary items are extremely challenging and technical.

There is little in the way of pre-reading vocabulary to hepl students be ready for what they are going to read in the text. Most of the reading questions in SPINE 6 can be answered by skimming rapidly through the text to get the main ideas or scanning for specific information For instance, on page 107 the reading questions of the topic "The Sweet Smell of Success" are textually explicit. These questions come as follows:

\section{Complete this informationsheet about Kenana Project}

1- LOCATION

2- STARTING DATE

3- MAIN PRODUCTS

4- MAIN BY-PRODUCTS

5- PROFIT IN DOLLARS FROM PRODUCTS

6- SHAREHOLDERS

While the second group questions looked like this:- 
1. What changes has the Kenana project caused in the area?

2- List all the advantages of the project.

3- Make a list of things which you think are 'environmentally friendly' and which are not.

Complete these questions with words or phrases from the passage, then answer the questions.

a. Is Sudanair a national or an company?

b. Which countries have many coffee...... ?

c. Which companies provide most for people in your area?

d. In which areas of Sudan is a problem because trees and plants do not grow?

Most of the questions of these texts focus on the low order thinking skills such as knowledge and comprehension.The answers for these questions are textually explicit, students will use the clues and mnemonic words to find the answer which is already stated in the passage. There are a few questions that develop the critical thinking skills of the learners such as analysis, synthesis and evaluation questions. The vocabulary activities in SPINE 6 provide students with different opportunities to study, reinforce and practice different aspects of words such as meaning, form and spelling. For example, on page 42,we can find these activities about silent letters:

\section{Look at these words and listen to your teacher say them.}

- live, thumb, wrist, know, buy, listen

- Which letters in each word are written but not spoken?

- We call these silent letters.

- Which words contain a silent letter?

- Write down the letters in each of these words.

- 1-colour 2-neighbour 3- give 4- big 5-height 6-cheque

- 7-humour 8-British 9-fan 10- judged 11- weather 12-comedy

Grammar activities include changing statements into the passive e.g:-

- $\quad$ write the past simple of verbs,

- $\quad$ fill in the blanks with the suitable preposition.

Many grammar task are contextualized in short reading passages where student is asked to determine the tense that fits best or the reason of using the tese in this context. For instance, on page113 we can find the following activity:

\section{Read the passage and notice the usage of the two tenses, then write the present simple in one column and the} present perfect in another.

Jane is a teacher. She teaches at the secondary level. She works very hard. She often teaches 8 hours a day and never complains because she enjoys her work very much.Since 1970 she has been teaching in AlNadha secondary school for girls. She has taught English, math and physics, and has helped many students to solve their learning problems. She is always very kind to her students who think she is the best teacher in the school.Jane has also helped with school administration for a number of years. She has collected books for the library and has raised money to build a stage for the school plays. She has also done many good things for the school. Jane is indeed a popular teacher and everyone admires her.

Then they are asked to nswer the folowing questions:

\section{Look again at the verbs.}

1) What is the present simple used to describe?

2) What is the present perfect used for?

This kind of activities which ask students to concentrate on the usage of one tense or more may offer learners good opportunities for better understanding of how these tenses work. Selection and usage of the appropriate tense is a skill seriously needed in real communication. 


\subsection{Analysis of Sudan and Jordan Examinations (2012-2015) according to the Four Skills of the English Language}

Notwithstanding that any teaching situation presupposes a testing situation. In Sudan and Jordan standardized English language examinations, there is a total deletion of testing listening and speaking skills. This complete absence of these two skills entirely contradicts the objectives of teaching English language in the two countries. Powers (2010) states: "The current trend in language learning and language testing continues to be away from testing individual skills and instead toward a comprehensive, integrated testing of language skills".

Listening, speaking, reading and writing skills are different as each skill is expected to serve specific purpose deferent from the other skills. Although testing one language skill separately from other skills may offer unplanned information about what the student can do with the other skills, it cannot provide a comprehensive assessment of the learners' overall communicative ability, which often maintains the use of different language skills-simultaneously- to integrate with one another.

Doing some content analysis, we analyzed the Sudan Secondary School Certificate and Jordan General Secondary Certificate English language examination papers from 2012 to 201; according to the four skills of the English language. We have specified the weight of each question. Then, we calculated the marks and frequency occurrence of each skill in all the exam papers of Sudan and Jordan and extracted the percentage of each one.

\subsection{Analysis of Jordan General Secondary Certificate English Language Examinations (2012 -2015)}

In 2012 and 2013, the reading skill represented 63\% of the English language examinations in Jordan for the total of $58.6 \%$ of the whole marks, whereas the writing skill gained $37 \%$ for the total of $41.4 \%$ of the whole marks of the exams.

Most of the reading texts in these examinations were extracted from the textbook of Action Pack 12 with trivial modifications. For example in 2012 in the summer session, we can find the reading topic of "Road tunnels" which is directly taken from a topic in the textbook of Action Pack12 on page 80. Also, in 2013 in the winter session, there is a topic about (Mustafah Salameh), which is found on page 73 of the textbook. See table (6) below.

Table 6. Analysis of Jordan general secondary certificate English language examinations (2012-2015) according to the four skills

\begin{tabular}{lllllllll} 
Skill & & & 2013 & & 2014 & & 2015 \\
\multirow{2}{*}{ Reading } & Items & Marks & Items & Marks & Items & Marks & Items & Marks \\
\cline { 2 - 9 } & $63.0 \%$ & $58.6 \%$ & $63.0 \%$ & $58.6 \%$ & $46 \%$ & $42 \%$ & $40.9 \%$ & $35 \%$ \\
\hline Writing & Items & Marks & Items & Marks & Items & Marks & Items & Marks \\
\cline { 2 - 10 } & $37.0 \%$ & $41.4 \%$ & $37.0 \%$ & $41.4 \%$ & $54 \%$ & $58 \%$ & 59.1 & $65 \%$ \\
\hline Sistening & items & items & marks & marks & items & marks & items & marks \\
\hline
\end{tabular}

The reading topic of "The difference between the life in a village or city" appeared in the examination paper of 2013, summer session. It is very much related to the reading passage "the end of Village life" on page 57. Most of the reading questions in these exams are related to the lower thinking skills: knowledge and comprehension because the answers of these questions are textually explicit as candidates will not exert much mental efforts in order to answer them.

The main function of knowledge testing is to examine the ability of the student to remember, cite or recognize accurate statements or (facts) in response to particular questions. Although more than just repeating from the memory is required for knowledge, the type of the question and the level of accuracy and correctness required; should not be too different from the techniques in which the knowledge was taught at the beginning of instructions. This means that the choices in the recognition the form of the question must be at the level of discrimination originally covered by the learning rather than at a completely different level.

In the assessment of comprehension, the learner is asked to recognize the inferences that are drawn from a 
specific communication. The level of these inferences may be more general than the communication itself and they should depend on more than one aspect in the communication. So when a student intends to interpret a communication, $\mathrm{s} /$ he must first be capable to translate each of the major parts of it and understand the rapports among its various parts, to reorder, or to rearrange it in his/her mind, so as to make some total view of what the communication contains and to relate it to his own experiences and ideas. Interpretation also includes competence in recognizing the main aspects of the communication. For instance, in the English language examination of 2012 winter session, the first question (Question One) is a reading one. What the testees will do to answer the different items of this question will be as follows:

(a) The phrase (similarities between Amman and Brasilia) in the first question will lead the learner directly to the answer.

(b) As stated in the question, the testee immediately moves to the last paragraph where he will find the answer, which is the specific purposes of the sectors and zones in Brasilia such as business and residential areas.

(c) In order to answer this question the learner should be able to understand that the sentence (Amman is an ancient city) has the same meaning as (Amman has a history going back over 8.000 years).

(d)This question is textually implicit, the testee should know that the word 'regulate' has the same meaning as (control).

(e) The learner should understand that the pronoun (it) refers to Amman city.

The percentage of the writing skill in these exams was estimated as $37 \%$ from all the items for the total of $41.4 \%$ of the marks. In 2014, the percentage of the reading skill questions decreased to $46 \%$ of all items in the exam for the total of $42 \%$ out of the whole marks of the exam, while the percentage of the writing skill questions increased significantly to reach $54 \%$ out of all items in the exam for the total of $58 \%$ of the whole marks.

In Jordan General Secondary Certificate English Language Examination (2015) the reading skill descended to $40.9 \%$ whereas the writing skill has risen to $59.1 \%$ out of all the items in the exam for the total of $65 \%$ out of the whole mark of the exam. Vocabulary questions included items such as filling in the spaces with the suitable word, choosing the correct meaning of the phrasal verbs and choosing the correct derivation. Most of these questions had similar activities in the textbook of Action Pack12. For example, question2 in the examination of 2014 (winter session) consists of the following items:

\section{Complete the following sentences with the suitable words derived from the words in brackets and write} the answers down in your answer book.

1) Our heating system is very old and extremely ............. . (inefficiency)

2) People should do their best to keep ......... in the world. (peaceful)

Similar Activities can be found in Action Pack 12 as on page 58:

Complete these sentences with words derived from the words in brackets.

(a) The Gulf of Aqaba is an area of great beauty. (nature)

(b) Careless drivers can seriously......... the safety of pedestrians. (threat)

(c) In my city there is a wide...... of entertainments to choose from. (vary)

(d) I'd like to live in a small..................... village near the sea. (peace)

(e) The storm damage is a lasting......... of the power of nature. (remind)

(f) I'll never forget the ............ I felt on my first day at school. (excite)

Grammar questions in the Jordan General secondary certificate English language examinations from 2012 to 2015 included items such as completion of a sentence; so that it would have similar meaning to the one before it, correction of the verb between brackets and choosing the suitable item. An example of these questions can be found in question 3 in the examination of 2015 (summer session) which include the following items:

Correct the verbs between brackets in the following sentences then write your answers down in your Answer Booklet.

1) According to our teacher's instructions all of our compositions in ink. He won't accept papers written in pencil. (write)

2) Instead of buying a new bicycle, why don't you have your old one ? (fix)

On page 53 of Action Pack 12, there are some items which ask students to perform the same activities: 
In these extracts from the recording the journalist is reporting what people said. Complete the sentences using the correct form of the verbs in brackets.

a. One of their sons told me that his parents............ (spend) every day of their lives together.

b. He said they ........... (always have) a good social life and....... (keep) in regular touch with their family, friends and neighbours.

c. He said he........ (be) not sure, but suggested that...

d. He added that they.......... (both be involved) in farming for most of their lives.

e. Mrs Chin said she ........... (never do) paid work.

The writing questions in Jordan examinations included writing emails, reports, recommendation letters, essays, biographies and articles. For example, in the exam of 2013 (winter session), candidates were asked to write about the following topics:

(a) Benefits of Voluntary work. (guided and compulsory)

(b) Imagine you have a large amount of money and you want to give it to an organization which helps people who are in need. Write an email to the organization mentioning whom you would like it to give the money to and how you want it to spend the money.

(c) Write a report about transport around the world mentioning the types of transport used in different environments and reasons of using them.

In the exam of 2014,(winter session), candidates were asked to write about the following topics:

a. How to communicate effectively.

b. Write an article about the responsibilities of families towards their old parents.

c. Write an article about the advantages and disadvantages of one long vacation and different short vacations.

Similar activities can be seen in the textbook of Action Pack 12. For example on page 55, students were asked to write an article giving advice to people of their own age, and on page 61 students have to write an email recommending a touristic site. Also, on page 67, learners are asked to write short biography about someone who has an interesting or unusual life. Most of the writing questions in these exams are related to the higher thinking skills: synthesis and evaluation. Students will exert remarkable mental efforts in order to answer them. Synthesis and evaluation are the higher thinking skills by which the critical thinking abilities can be attained. Bloom's et.al (1956) defined synthesis as "the placing together of elements and parts in order to shape a new whole". This is the classification in the cognitive domain that clearly shows the creative abilities of the student. However, it should be highlighted that this is not completely pure creative abilities because generally the student is expected to work within the limits set by specific problems, materials, or some theoretical and methodological framework. In synthesis, the learner who tries to accomplish this objective must put different elements together into a new structure or pattern not being designed before. The student's efforts should produce a product that can be noticed through one or more of the senses and should be different from the materials s/he started to work with.

The main objective of assessing the evaluation ability of a learner is to see whether s/he is able to judge a document correctly as being coherent or incoherent, accurate or inaccurate, carefully done or carelessly written. Also, a learner should make a general evaluation of the work with regard to accuracy and cite the specific points which are accurate or inaccurate as well as giving reasons why they the situation is are judged in this way. The performance of the evaluation objective can, in several cases, be the introduction to the attainment of new information. The multiple-choice or other recognition forms are not recommended can be used in testing the evaluation category objectives because they are connected with reactions to stimuli. Bloom et al (1956) mention that the criteria used in the performance of evaluation can be classified into techniques, rules, standards or the comparison of the work with other works in the field. So, evaluation should include the classification of the material in order to use the suitable criterion for judgment.

In Jordanian General Secondary Certificate Examinations from 2012 to 2015 the critical thinking questions are related significantly to the writing skill and the higher thinking skills: synthesis and evaluation in particular. For example, synthesis questions require students to write paragraphs and give suggestions for topics such as improving healthy sleep habits, new methods that help people to deal with their fear in long tunnels, how to make difficult decisions or improving healthy sleep habits. Depending on the ideas and vocabulary stated in the text or a table the learner will create his own paragraph. The testee should write correct sentences connected with the appropriate linking words. Evaluation questions are linked with free writing. In free writing questions, the 
student should freely write a paragraph of nearly 80 words about topics such: as the effects of doing housework on children's personality, the advantages of raising animals in houses or farms, human values in building nations or marriage customs and traditions. The learner has to write about the different aspects of the topic. $\mathrm{S} / \mathrm{He}$ has to communicate his own ideas and judgments clearly using comprehensive information joined by suitable conjunctions. The paragraph should also be free of spelling mistakes.

\subsection{Analysis of Sudan Secondary Certificate English Language Examinations from 2012 to 2015}

Table 7 shows the analysis of Sudan secondary certificate English Language Examinations from 2012 to 2015 according to the four skills of the English language in case those students answered the language optional questions, taken from SPINE series, in section (A) of part five.

Table7. Sudan secondary certificate English Language Examinations from 2012 to 2015 according to the four skills

\begin{tabular}{|c|c|c|c|c|c|c|c|c|}
\hline Academic & 2012 & & 2013 & & 2014 & & 2015 & \\
\hline \multirow[t]{2}{*}{ Reading } & Items & Marks & Items & Marks & Items & Marks & Items & Marks \\
\hline & $49 \%$ & $40 \%$ & $49 \%$ & $40 \%$ & $49 \%$ & $40 \%$ & $40 \%$ & $\% 35$ \\
\hline \multirow[t]{2}{*}{ Writing } & Items & Marks & Items & Marks & Items & Marks & Items & Marks \\
\hline & $51 \%$ & $60 \%$ & $51.0 \%$ & $60 \%$ & $51 \%$ & $60 \%$ & $60 \%$ & $\% 65$ \\
\hline \multirow[t]{2}{*}{ Listening } & items & items & marks & marks & items & marks & items & marks \\
\hline & $00.0 \%$ & $00.0 \%$ & $00.0 \%$ & $00.0 \%$ & $00.0 \%$ & $00.0 \%$ & $00.0 \%$ & $00.0 \%$ \\
\hline \multirow[t]{2}{*}{ Speaking } & items & items & marks & marks & items & marks & items & marks \\
\hline & $00.0 \%$ & $00.0 \%$ & $00.0 \%$ & $00.0 \%$ & $00.0 \%$ & $00.0 \%$ & $00.0 \%$ & $00.0 \%$ \\
\hline
\end{tabular}

As can be seen from the table above, in 2012, 2013 and 2014, the reading skill represented 49\% of the English language examinations in Sudan, for the total of $40 \%$ of the whole marks, whereas the writing skill gained $51 \%$ for the total of $60 \%$ of the whole marks of the exams. Most of the reading questions in these exams are related to the lower thinking skills: knowledge and comprehension because the answers of these questions are textually explicit and candidates will not exert much mental efforts in order to answer them.

In Sudan Secondary Certificate English Language Examination (2015) the reading skill descended to $40 \%$, whereas the writing skill went up to $60 \%$ out of all the items in the exam for the total of $65 \%$ out of the whole mark of the exam. For example, in the English language examination of 2014, section (A) of part five contains four questions, three of them are writing and one of them is a reading question. What the candidates will do in order to answer the different items of this section will be as follows:

\section{Section (A) - Question (1)}

The testee should write a letter to the Nile Petroleum General Manager to apply for the job of a secretary as advertised in Sudani daily newspaper. The student should mention his /her qualifications, age and why he is applying for this job. The sentences should be structurally accurate and linked by the suitable conjunctions.

\section{Question (2)}

This question comprises five items. Answering this question, the testee should complete sentence (B) so that it has the same meaning as sentence (A).In order to complete these sentences the learner has to apply some grammatical rules.

\section{Question (3)}

There are five items in this question. The testee has to choose the suitable preposition from the list and complete each sentence. The learner will use the words in the sentences as keywords that will lead him/her to the correct option. 


\section{Question (4)}

In this question, the student, in no more than 25 words, has to summarize how Martin Luther King was aware that the blacks were not treated as equal citizens. The learner should communicate his/her ideas clearly and write correct sentences linked by the suitable connectors. The new paragraph should be free of spelling mistakes.

As can be seen from the description above, most of the questions in this section are writing questions. So, for the students who answer this section; the portion of the writing skills will rise to $60 \%$ out of all the questions for the total mark of $65 \%$ of the whole mark of the exam.

The testing of the writing skills in Sudan secondary certificate English language examinations is remarkably related to the synthesis thinking skill order. Candidates are asked to write guided compositions, letters and summarize paragraphs. All these writing activities require students to place together elements and parts in order to make new sentences or paragraphs. From the analysis of these items, we can notice the absolute absence of listening and speaking skills.

Table 8 shows the percentage of the items and marks in Sudan secondary certificate English Language Examinations from 2012 to 2015 according to the four skills of the English language in case that student answered the literature optional questions in section (B) of part five.

Table 8. The four skills of the English language

\begin{tabular}{|c|c|c|c|c|c|c|c|c|}
\hline \multicolumn{9}{|c|}{ Academic Year } \\
\hline Skill & \multicolumn{2}{|l|}{2012} & \multicolumn{2}{|l|}{2013} & \multicolumn{2}{|l|}{2014} & \multicolumn{2}{|l|}{2015} \\
\hline \multirow{3}{*}{ Reading } & & & & & & & & \\
\hline & Items & Marks & Items & Marks & Items & Marks & Items & Marks \\
\hline & $70.3 \%$ & $60 \%$ & $70.3 \%$ & $60 \%$ & $70.3 \%$ & $60 \%$ & $70.3 \%$ & $60 \%$ \\
\hline \multirow{2}{*}{ Writing } & Items & Marks & Items & Marks & Items & Marks & Items & Marks \\
\hline & $29.7 \%$ & $40 \%$ & $29.7 \%$ & $40 \%$ & $29.7 \%$ & $40 \%$ & $29.7 \%$ & $40 \%$ \\
\hline
\end{tabular}

As can be seen from the table above, answering the literature section raises the portion of the reading skill up to $70.3 \%$ out of all the items of the exam for the total of $60 \%$ of the whole marks. Consequently, the questions of the writing skill descended to $29.7 \%$ for the total of $40 \%$ of the whole mark. The literature sections is completely devoted for the knowledge thinking skill which is considered as the lowest thinking skill, student will just remember the incident in the story and choose the correct option. For instance, in Sudan secondary School Certificate English language examination of 2013, the mental effort which the candidate exerts will be as follows:

\section{Section (B): This is the literature section. It contains supplementary readers: e.g Things Fall Apart and} Treasure Island.

\section{First: Things Fall Apart}

(A): In order to answer these three open-ended questions, the student will just recollect the answers of these questions relying on his earlier reading of this story.

(B) This part contains five multiple-choice questions. The candidate should answer these questions by selecting the correct answer out of four written choices.

(C) The learner has to match five items correctly. The student will match group (A) with group (B) by putting the correct letter from (B) in front of $(A)$ in column $(C)$.

\section{Second: Treasure Island}

(A) The testee has to answer three open-ended questions. The learner will just recall the answers of these questions depending on his previous reading of the story.

(B) This part requires the candidate to answer five multiple-choice questions. The learner, in order to answer these questions, should decide on the best choice out of four written answers.

(C) Five (true) or (false) questions will be answered by the learner who will depend on his earlier reading of the story to recognize which statement is correct and which one is wrong. 
Testing literature should be deeper, the testee could be asked to write, in a simplified language, about the plot or the main character of the story.

The reading passages in Sudan Examinations were not taken directly from the textbook of SPINE 6 but the vocabulary and the cultural aspects were familiar to the students. Most of these texts were related to the daily life of the Sudanese people. For instance, the comprehension passage in the exam of 2012 was as follows:

Ahmed was nine years old and lived with his family in a village in Gazira. He was part of a large family of six brothers and five sisters. Ahmed looked after the family sheep. He always made sure that they had the best grass to eat. So they were very fat and healthy, and give lots of milk for his all family. In the Gazira region farmers grow cotton and wheat. One year, however, the crops were attacked by hungry insects. The farmers were very worried and sprayed their crops with a pesticide. This was hard expensive work. But the pesticide was very strong and killed most of the insects. The crops grew well and the farmers were happy. The next year the farmers had to spray their crops again because some of the insects which had not been killed had multiplied and were attacking the crops again.

After the crops had been harvested, the field was very good grazing land. Ahmed's sheep went to the best fields. These were the fields which had been sprayed with pesticide and the sheep ate much grass. Soon the sheep began to grow thin and did not produce much milk as they used to. Ahmed did not understand why the sheep were ill. He did not know that the green grass was covered with pesticide and the pesticide was making these sheep ill.

In Sudan examinations 2012, 2013, 2014 and 2015 students were asked to write a composition about "How Amna Hamid, who was a widow, helped her children. Then they were asked to write about Trees, Education and Water respectively. These topics can be found in the textbook of SPINE 6, for example, the topic of Amna Hamid, is generally about the problems that women face in their life, this topic is reviewed in chapter five, where different activities and tasks were devoted to deal with it. Correspondingly, the topics of trees, education and water were reflected in different parts of the textbook of SPINE 6. Letter writing and summary questions exist in all the Sudanese examinations. In SPINE 6, there are many models for letter writing activities but there is only one activity of summary in the writing section of chapter 2on pages 33 and 34 . We think that it is easy for the candidates to write about these topics since they have already acquired the needed vocabulary to achieve this mission. Vocabulary questions included items such as filling in the spaces with the suitable word and adding a suffix or prefix to form the correct derivation. Most of these questions have similar activities in the textbook of SPINE 6 . For example, in chapter 10, on page 162, we can find the following activity:

\section{Use the words to fill in the spaces below.}

fuel-available - local-remote-grind-run out

I live in a small village a very long way from the town. It is really a .............. village. We depend on the ........... shops for our daily needs. Many of the things we need, however, are not ......... in the village shops. The only things you can find in the village are the flour mill where we can buy ............ our grain. Sometimes, though we need to drive to a town. Many times I have of . on the way.

Some vocabulary questions have been taken directly from the textbook of SPINE 6. For example, in the examination of 2012 in part 4 section (c), we can find the following question :

\section{Choose the suitable word from the list below to complete the following text:}

\section{by-founded-plantation-between-major}

The Kenana Sugar ............... is located near Rabak. It was in 1975 as a joint project some multi- national corporations, some neighbouring Arab countries and the Sudanese government, which is the ............... share holder. The scheme is now managed ...... the Kenana sugar Company.

This text was directly extracted from the reading passage "The Sweet Smell of Success" in chapter7, on page 1 06 . Grammar questions included items such as complete sentence 'B' so that it has the same meaning as sentence 'A', put the verbs between brackets in their correct form and choose the suitable preposition from the list to fill in the spaces. For example, in the examination of 2015, in part one, section 'A', we can find the following items:

\section{Put the verbs between brackets in their correct form:}

1- Those deer ................... away now. (run)

2-It .......... heavily last year. (rain)

3- The sun and the moon ................. us light. (give)

4- While some boys ......... in the Nile, a storm blew suddenly. (swim) 
5-Some doctors in London for many years and they haven't returned to the Sudan yet. (work)

6- Samia usually enjoys the news on T.V. (watch)

7- If Osama rich, he would build a hospital. (be)

Similar activities can be found in Spine 6, for instance, in chapter 4, page 60, we can find the following activity:

Complete this dialogue. Put the verbs in brackets in the correct form.

Sara: Fuad! How nice to see you! What ....... (you/do) these days?

Fuad: I .... (train) to be a supermarket manager.

Sara: Really? What's it like? .... (you/ enjoy) it?

Fuad: It's all right. What about you?

Sarah: well, actually I ....... (not work) at the moment. I .... (try) to find a job but it's not easy. But I'm very busy I ...... (decorate) my flat.

Fuad: ........ (you/do) it alone?

Sarah: No, some friends of mine (help) me.

Grammar activities included changing statements into the passive, write the past simple of verbs, and fill in the blanks with the suitable preposition. Many grammar tasks are contextualized in short reading passages or dialogues where student is asked to determine the tense that fits best or the reason of using the specific tense in this context.

\section{Findings}

\subsection{Hypothesis One}

The Sudan Secondary School Certificate and Jordan General Secondary Certificate English Language Examinations are comprehensive examinations and expected to reflect the objectives in (SPINE 6 and Action Pack 12).

The analysis of the Sudan and Jordan examinations and the textbooks of SPINE 6 and Action Pack 12 showed absence of testing listening and speaking skills which considers these examinations incomprehensive. A good test must be comprehensive to cover all or almost all the aspects of the course contents which are embedded in that specific syllabus. The comprehensive test must as well attain the educational objectives of the target course or the unit taught to students.

As in Bani Abdelrahman (2010) the Ministry of Education in Jordan (2008) stated that students are expected to acquire a variety of skills and objectives. Listening and speaking are at the head of these objectives:

\section{A-Listening}

(a) Develop advanced listening strategies in academic and authentic contexts.

(b) Demonstrate understanding of directions, presentations and performances in a variety of authentic contexts.

\section{B- Speaking}

(a) Speak English words and sentences clearly and fluently in a variety of academic authentic contexts.

(b) Use words and sentences to participate in discussions and conversations in a variety of academic authentic contexts

(c) Take part in a variety of well- prepared presentations to the class in a variety of academic authentic contexts.

We have counted all the activities and tasks in Action Pack 12 and found that the activities and tasks of the listening and speaking skills represent $43 \%$ throughout the whole textbook. But we found that, there is a complete absence of testing listening and speaking skills in Jordan General Secondary School English language Examinations between 2012 and 2015.

In SPINE 6 Teacher's Book, there are three aims of this textbook: by the end of SPINE 6 programme, pupils should have.

(a) Recycled and reinforced previously learned language.

(b) Developed further the four language skills with special emphasis on Reading and writing.

(c) The ability to understand and use English which is relevant to their needs and which will help them to communicate with adequate accuracy and fluency in all situations. (Alfaki,1997. P, 5). 
We found that there was complete absence of the listening skill in the textbook. It is our belief that the listening skills are important for effective communication in our daily life. These skills are important because they foster good self-esteem, maximize productivity, improve relationships, and even assist in becoming a fluent speaker. The absence of the listening skill activities in SPINE 6 textbook totally contradicts the objectives of the ministry of Education as embedded in the teacher's manual of SPINE 6 to further develop the four language skills with special emphasis on reading and writing. The complete absence of the listening skills activities and tasks; may be due to the poor teaching environments, where educational aids such as: language laboratories, cassette recorders or CD players are lacking. The absence of testing speaking and listening skills make the standardized English language examinations in Sudan and Jordan as incomprehensive because it does not comply with the objectives of language pedagogy in general and in Sudan and Jordan as case study - in particular.

\subsection{Hypothesis Two}

The Sudan Secondary School Certificate and Jordan General Secondary Certificate English Examinations have content validity and comprise representative samples of the language skills.

The analysis of Sudan Secondary School Certificate and Jordan General Secondary Certificate English language examinations from 2012 to 2015 and the preparatory resources designed for these exams, SPINE 6 and Action Pack 12, have revealed that these examinations have content validity. A test is said to have content validity if its contents constitute and provide representative samples of the language skills, structures, etc. Content validity is an important notion for the measurement of skills and knowledge that are frequently employed in evaluation studies. Content validity is often evaluated by examining the plan and procedures used in test construction. According to (Hughes, 1989), content validity is the accumulation of evidence to support a specific interpretation of the test results. To demonstrate content validity, testers investigate the degree to which a test is a representative sample of the content of whatever objectives or specifications the test is originally designed to measure.

Most of the reading texts in Jordan General Secondary Certificate English language examinations from 2012 to 2015 were directly taken from the textbook of Action Pack12 with trivial modifications. For example in 2012 in the summer session, we can find the reading topic of "Road tunnels" which is directly taken from a topic in the textbook of Action Pack12 on page 80. Also, in 2013 in the winter session, there is a topic about Mustafah Salameh, which exists on page 73 of the textbook. The reading topic of "The difference between the life in a village or city" that appeared in the examination paper of 2013, summer session, has deeper relation with the reading passage "the end of Village life" on page 57.

The reading passages in Sudan Secondary School Certificate English language Examinations from 2012 to 2015 were not taken directly from the textbook of SPINE 6 but the vocabulary and the cultural aspects are familiar to the students. Most of these texts were related to the daily life of the Sudanese people.

In Sudan examinations 2012, 2013, 2014 and 2015 students were asked to write a composition about "How Amna Hamid, who was a widow, helped her children, Trees, Education and Water respectively. These topics can be found in the textbook of Spine 6, for example, the topic of Amna Hamid, Correspondingly, the topics of trees, education and water were reflected in different parts of the textbook of SPINE 6.

Letter writing and summary questions exist in all the Sudanese examinations. In SPINE 6, there were many models for letter writing activities but there is only one activity of summary in the writing section of chapter 2 on pages 33 and 34 .

The writing questions in Jordan examinations included writing emails, reports, recommendation letters, essays, biographies and articles. Similar activities can be seen in the textbook of Action Pack 12. For example on page 55 , students were asked to write an article giving advice to people of their own age, and on page 61 students have to write an email recommending a touristic site. Also, on page 67, learners are asked to write short biography about someone who has an interesting or unusual life.

In Jordan examinations also vocabulary questions included items such as filling in the spaces with the suitable word, choosing the correct meaning of the phrasal verbs and choosing the correct derivation. Most of these questions have similar activities in the textbook of Action Pack12. In Sudan examinations, vocabulary questions included items such as filling in the spaces with the suitable word and adding a suffix or prefix to form the correct derivation. Most of these questions have similar activities in the textbook of SPINE 6.

Grammar questions in the Jordan General secondary certificate English language examinations from 2012 to 2015 included items such as completion of a sentence so that it has similar meaning to the one before it, correction of the verb between brackets and choosing the suitable item. These questions have similar activities 
and tasks in the textbook of Action back12. Grammar questions in the Sudan secondary school certificate English language examinations from 2012 to 2015 included items such as complete sentence 'B' so that it has the same meaning as sentence ' $\mathrm{A}$ ', put the verbs between brackets in their correct form and choose the suitable preposition from the list to fill in the spaces. Same tasks can be found in the textbook of SPINE 6.

We can infer from what has been stated above that the Sudan Secondary School Certificate and Jordan General Secondary Certificate English language examinations from 2012 to 2015 had content validity, so they are content-based examinations.

\subsection{Hypothesis There}

The Sudan Secondary School Certificate and Jordan General Secondary Certificate English Language Examinations have beneficial backwash.

Tables 4, 6, 7, 8 revealed that the Sudan Secondary School Certificate and Jordan General Secondary Certificate English language examinations from 2012 to 2015 have beneficial backwash on reading and writing skills but they totally neglected testing the listening and speaking skills. Assessment is a vital constituent of education, as it determines whether or not the aims of instruction are being attained. Washback is the effect of test or testing program on teaching and learning. Washback can be beneficial if the test is considered important and the preparations for it cover all teaching and learning skills.

According to (Hughes, 1989), harmful backwash is produced when there is a difference between the content of the course and the testing techniques on one side, and the objectives of the course on the other side. Test takers can be affected by three aspects of the testing procedures. First, the experience of taking and in some cases, of preparing for the test. Second, the feedback they receive about their performance on the test. Third, the decisions that may be made about them accord to their test results. It is also argued that teachers, in any educational programme are familiar with the amount of influence of testing on their instruction. Even though the fact that teacher may prefer to teach certain material in a specific way, they may discover that teaching to the test is more or less unavoidable. The term teaching to the test means doing something in teaching that may not be compatible with teachers own values and goals, or with the values and goals of the educational programme. The term teaching to the test' implies that the test is not so conceived, and that... the teaching that may not be compatible with (their) own values and goals, or with the values and goals of the instructional program' (Bachman \& Palmer, 2010).

One way to lessen the potential negative impact on instruction is to change the way we test so that the characteristics of the test and test tasks must correspond more closely to the objectives of the syllabus. The Sudan Secondary School Certificate and Jordan General secondary Certificate English language examinations from 2012 to 2015 may have beneficial washback on the reading and writing skills. The absence of testing listening and speaking skills yields harmful backwash concerning these two skills.

\subsection{Hypothesis Four}

The Sudan Secondary School Certificate and Jordan General Secondary Certificate English Language Examinations can be used as benchmark of the effectiveness of teaching and learning performance in the classroom and device of measurement of learner's acquisition of English as a foreign language.

Shute and Becker (2010) stated that assessment is linked with various aims. For instance, if your goal was to improve an individual's learning, and you intend to determine his/her development towards an educational aim, you could: (a) administer a quiz; (b) view a portfolio of his/her work; (c) ask a peer to assess her progress; (d) watch the pupil solving a complicated class work; (e) review his/ her lab reports .

You then need to use the data collected by these assessments to make decisions about the learner or guide $\mathrm{him} / \mathrm{her}$ to more learning activities.

As a result of time or financial restrictions, test developers, who use scores to make decisions about test takers' qualifications for work or study, ignore important skills or abilities.

As there is no testing for listening and speaking skills in the Sudan Secondary school Certificate and Jordan General Secondary Certificate; so these examinations can be relatively used as benchmark of the effectiveness of teaching and learning performance in the classroom; although they could be considered as tools of measurement of learners acquisition of the English language reading and writing skills.

\section{References}

Alfaki, I. (1997). SPINE 6: Teacher's Book. Khartoum.Tarbia Printing press. 
Alfaki, I. (2014). Sudan English Language Syllabus: Evaluating Reading Comprehension. Questions Using Bloom's Taxonomy.

Al-Ghazo, A., \& Samdi, M. (2013). A Content Analysis of the English Reading texts Authenticity in student's Book of Action Pack Eleven in Jordan. European Scientific Journal.

Bani Abdelrahman, M. (2010). An Analysis of "Jordan Opportunities" Objectives in the General Secondary Certificate Examination of English.

Bachman, L., \& Palmer, A. (1996). Language Testing in Practice: Designing and Developing Useful Language Tests. Oxford. Oxford University Press.

Haines, S. (2010). Action Back 12: Student's Book. London. York Press.

Kilbey, L. (2010). Action Back 12: Teacher's Book. London. York Press.

Powers, D. (2010).The Case for a Comprehensive, Four-Skills Assessment of English-Language Proficiency.

Shute, V. J., \& Becker, B. J. (2010). Prelude: Issues and assessment for the 21 st century. In V. J. Shute, \& B. J. Becker (Eds.), Innovative assessment for the 21st century: Supporting educational needs (pp. 1-11). New York: Springer. https://doi.org/10.1007/978-1-4419-6530-1_1

Alnofaie, H. (2013). A framework for implementing critical thinking as a language pedagogy in EFL preparatory programmes. Thinking Skills and Creativity, 10, 154-158. https://doi.org/10.1016/j.tsc.2013.09.002

Dörnyei, Z. (1994). Motivation and motivating in the foreign language classroom. Modern Language Journal, 78 , 273-284. https://doi.org/10.1111/j.1540-4781.1994.tb02042.x

Dörnyei, Z. (1998). Motivation in second and foreign language learning. Language Teaching, 31, 117-135. https://doi.org/10.1017/S026144480001315X

Fahim, M., \& Hajimaghsoodi, A. (2014). The relationship between motivation and critical thinking abilityof Iranian EFL learners. International Journal of Language Learning and Applied Linguistics World, 5(2), 605-619.

Fahim, M., \& Komijani, A. (2010). Critical thinking ability, L2 vocabulary knowledge, and L2 vocabulary learning strategies. Journal of English Studies, 1(1), 23-38.

Gardner \& Lambert (1959). Fifty years and counting. Paper presented at the Canadian Association of Applied Linguistics.

Gardner, R. C., \& Lambert, W. E. (1972). Attitudes and motivation in second language.

Gonzales, R. D. L. C. (2000). Filipino Foreign Language Motivation: In Search of Internal Structures and External Links. A Paper presented as a Professorial Chair Lecture, De La Salle University-Manila.

Gonzales, R. D. L. C. (2006). Conceptual and psychometric properties of a foreign language learning motivation questionnaire. Philippine Journal of Psychology, 39(1), 76-97.

Grosser, M. M., \& Nel, M. (2013). The relationship between the critical thinking skills and the academic language proficiency of prospective teachers. South African Journal of Education, 33(2), 1-17. https://doi.org/10.15700/saje.v33n2a639

Hashemi, M. R., \& Zabihi, R. (2012). Does critical thinking enhance EFL learners' receptive skills? Journal of Language Teaching and Research, 3(1), 172-179. https://doi.org/10.4304/j1tr.3.1.172-179

Javier, M. M. (2001). Language proficiency and mental ability as related to critical thinking and academic achievement of secondary students: A causal modeling study. Unpublished master's thesis, Philippine Normal University, Manila.

Langevin Team. (2017). How to Apply Bloom's Taxonomy to the Testing Process

Lai, E. R. (2011). Critical Thinking. A literature review.

Lin, M., \& Mackay, C. (2004). Thinking through modern foreign languages. Cambridge: Chris Kingston.

Lopez, M. Y. (2004). The development and validation of critical thinking infusion lessons in communication skills for freshman college students. Unpublished doctoral dissertation, Philippine Normal University, Manila.

Lopez, Marcos Y., \& Richard, D. L. C .G. (2017). Examining the Relationship between Foreign Language Learning Motivation and Critical Thinking Motivation: The Case of Filipino Foreign Language Learners. 
Retrieved Feb. 2017

Rashid, R. A., \& Hashim, R. A. (2008). The relationship between critical thinking and language proficiency of Malaysian undergraduates. Proceedings of the EDU-COM 2008 International Conference.

Ushioda, E. (1994). L2 motivation as a qualitative construct. Teanga, 76-84.

Ushioda, E. (2001). Language learning at university: Exploring the role of motivational thinking. In Z. Dörnyei, \& R. Schmidth (Eds). Motivation and second language acquisition (pp. 93-125). Honolulu, HI: University of Hawai'I Press.

Ushioda, E. (2008). Motivation and good language learners. In C. Griffiths (Ed.). Lessons from good language learners (pp. 19-34). Cambridge, England: Cambridge University. https://doi.org/10.1017/CBO9780511497667.004

\section{Copyrights}

Copyright for this article is retained by the author(s), with first publication rights granted to the journal.

This is an open-access article distributed under the terms and conditions of the Creative Commons Attribution license (http://creativecommons.org/licenses/by/4.0/). 